rev.relac.int.estrateg.segur.13(2):39-71,2018

\title{
Posibilidades de manejo conjunto de la reserva de biósfera Seaflower en la frontera marítima colombo-nicaragüense*
}

\author{
Christian Chacón** \\ Silvia Mantilla*** \\ Raúl Román Romero****
}

\section{Resumen}

El artículo explora las posibilidades de una integración transfronteriza en el espacio marítimo limítrofe entre Colombia y Nicaragua, a partir del manejo conjunto

* Este artículo es resultado del proyecto de investigación La vecindad y la integración fronteriza entre Colombia y los países del Gran Caribe, financiado por la coordinación de investigación de la sede Caribe y la Vicerrectoría de Investigación de la Universidad Nacional de Colombia.

** Politólogo, candidato a Magíster en Estudios Políticos de la Universidad Nacional de Colombia. Miembro del grupo de investigación en Relaciones Internacionales y Asuntos Globales (RIAG), de la Universidad Nacional de Colombia. Correo electrónico: chaconh@ unal.edu.co

*** Profesora e investigadora de la Facultad de Derecho, Ciencias Políticas y Sociales, de la Universidad Nacional de Colombia, sede Bogotá. PhD. en Migraciones y Conflictos en la sociedad global. Politóloga internacionalista. Correo electrónico: scmantillav@unal.edu.co

**** Profesor de la Universidad Nacional de Colombia, sede Caribe. Doctor en Historia de América Latina, Magister en Estudios el Caribe e historiador. Correo electrónico: rromanr@unal.edu.co 
de la Reserva de Biósfera Seaflower. Se utilizan las teorías de los Bienes Comunes de Ostrom y los Regímenes Internacionales como marco para el abordaje de conflictos por recursos, en un escenario de litigio e indeterminación territorial, y se analiza el marco institucional de las Reservas de Biósfera Transfronterizas de la Unesco junto con algunas experiencias mundiales en desarrollo. Finalmente, se hace una caracterización multidisciplinar del valor social y ambiental de la Reserva de Biósfera Seaflower y de su naturaleza transfronteriza, para demostrar que la situación de conflicto e indeterminación en la zona pone en riesgo su desarrollo y protección normales, por lo que los actores locales implicados tienen un rol fundamental en las iniciativas de manejo conjunto, lideradas por los Estados implicados.

Palabras clave: Colombia; integración transfronteriza; mar Caribe; Nicaragua; Reservas de Biósfera.

\title{
Possible Joint Management of the Seaflower Biosphere Reserve in the Colombian-Nicaraguan Maritime Border
}

\begin{abstract}
The article outlines a proposal for cross-border integration in the maritime boundary between Colombia and Nicaragua based on the joint management of the Seaflower Biosphere Reserve. Ostrom's Theory of Common-Pool Resource and Regime Theory are used as a framework to address conflicts over resources in litigation and territorial indeterminacy scenarios. The institutional framework of UNESCO's Cross-Border Biosphere Reserves is also discussed, along with some developing global experiences. Finally, the social and environmental value of the Seaflower Reserve and its cross-border nature is characterized from a multidisciplinary perspective to prove that conflict and indeterminacy in the area jeopardize its normal development and protection; therefore, local actors play a fundamental role in joint management initiatives led by the nations involved.
\end{abstract}

Keywords: biosphere reserves; Caribbean sea; Colombia; cross-border integration; Nicaragua. 


\section{Possibilidades de manejo conjunto da reserva de biosfera Seaflower na fronteira marítima colombo-nicaraguense}

\section{Resumo}

O artigo explora as possibilidades de uma integração transfronteiriça no espaço marítimo limítrofe entre a Colômbia e a Nicarágua, a partir do manejo conjunto da Reserva de Biosfera Seaflower. Utilizam-se as teorias dos Bens Comuns de Ostrom e os Regimes Internacionais como marco para a abordagem de conflitos por recursos, em um cenário de litígio e indeterminação territorial, e se analisa o marco institucional das Reservas de Biosfera Transfronteiriça da UNESCO junto com algumas experiências mundiais em desenvolvimento. Finalmente, faz-se uma caracterização multidisciplinar do valor social e ambiental da Reserva de Biosfera Seaflower e de sua natureza transfronteiriça, para demonstrar que a situação de conflito e indeterminação na zona põe em risco seu desenvolvimento e proteção normais, motivo pelo qual os atores locais implicados têm um rol fundamental nas iniciativas de manejo conjunto, lideradas pelos Estados implicados.

Palavras-chave: Colômbia; integração transfronteiriça; mar Caribe; Nicarágua; Reservas de Biosfera.

\section{Introducción}

En el año 2000, el Departamento Archipiélago de San Andrés, Providencia y Santa Catalina fue declarado Reserva de la Biósfera Seaflower por parte de la UNESCO, con un área marina protegida (AMP) de aproximadamente 65000 $\mathrm{m}^{2}$. En este entramado medioambiental conviven gran cantidad de especies endémicas, manglares, arrecifes de coral y vegetación marina, entre otros.
Por tanto, este espacio es de enorme importancia no sólo para la estabilidad ecológica de la región sino para la humanidad.

Un año después, Nicaragua entabló una disputa por la definición de sus límites sobre la zona mencionada, lo que produjo conflictos jurídicos y políticos que han puesto en cuestión la soberanía colombiana sobre el espacio marítimo e insular, que ostentó 
desde 1928 con el Tratado EsguerraBárcenas ${ }^{1}$. Más allá de recapitular al detalle los litigios alrededor de este conflicto limítrofe, vale la pena hacer énfasis en el último fallo de la Corte Internacional de Justicia (CIJ), la cual desestimó el meridiano 82 como límite marítimo entre ambos Estados y reconfiguró toda la zona del Mar Caribe, con efectos negativos concretos no sólo en términos políticos sino también con repercusiones ambientales vinculadas con la Reserva de Biósfera mencionada.

En 2013, un delegado de la UNESCO declaró, para un diario nicaragüense, que era "insólito" que el espacio de reserva marítima hubiera sido separado políticamente entre dos Estados y afirmó que el espacio debe ser administrado por los dos países, cada cual en su parte correspondiente (Nicaragua y Colombia deberán compartir reserva Seaflower, 2013). Esta declaración no es trivial, puesto que la importancia de la Reserva no sólo está vinculada a las responsabilidades estatales, sino también a los usos y las formas de apropiación que se hacen de la misma zona por parte de los pobladores locales.
Con lo anterior en mente, vale la pena preguntarse icuál debe ser la forma más apropiada para lograr una administración "compartida" de la Reserva de Biósfera Seaflower? Naturalmente, la variedad de alternativas que se pueden presentar es amplia, pero, con el ánimo de reconocer no sólo el conflicto desde los Estados-nación, sino también el papel relevante que juegan los actores locales, se hace aquí una propuesta que capaz de llevar a buen puerto la situación de indeterminación que el fallo más reciente de la CIJ estableció con el trazado de unas nuevas líneas fronterizas entre Colombia y Nicaragua.

En el presente artículo se demuestra que el diferendo limítrofe entre Colombia y Nicaragua por los derechos territoriales y marítimos en el Caribe ha creado una situación de conflicto e indeterminación en la zona. Conflicto que pone en riesgo la protección y el normal desarrollo de la reserva de biósfera Seaflower. La reserva contiene invaluables recursos, hábitats y corredores ambientales que se insertan en el amplio contexto del Gran Caribe, traspasando los límites territoriales en-

1 El 6 de diciembre de 2001, Nicaragua inició ante la CIJ una demanda contra Colombia por la soberanía sobre el territorio y la delimitación marítima en el mar Caribe. El 13 de diciembre de 2007, la CIJ en su primer fallo se declaró competente para dirimir el litigio entre Colombia y Nicaragua, reconociendo a Colombia su soberanía sobre las islas de San Andrés, Providencia y Santa Catalina, pero adujeron que aún era necesario definir la frontera marítima y la apropiación sobre los cayos y otras formaciones terrestres. Por ello, en la sentencia del 12 de noviembre de 2012, la ClJ definió los nuevos límites marítimos, otorgando a Nicaragua cerca de $40 \%$ del mar territorial que anteriormente administraba Colombia. Al mismo tiempo, otorgó a ese país la soberanía sobre los cayos adyacentes. Posteriormente el 16 de septiembre de 2013, Nicaragua demandó nuevamente a Colombia por incumplimiento en la aplicación del fallo, además de reclamar una Plataforma Marítima Continental Extendida. El 17 de marzo de 2016, la ClJ decidió que es competente para juzgar ambas demandas de Nicaragua, lo que supone a Colombia una futura sentencia, posiblemente desfavorable a sus intereses marítimos y territoriales. 
tre los países, lo cual exige un manejo conjunto de la reserva, que garantice el buen uso de sus recursos. Existe, además, todo un régimen internacional apoyado por la UNESCO y orientado a la consolidación de Reservas de Biósfera Transfronterizas, que puede ser puesto en práctica para el caso que se analiza aquí.

Por otra parte, se hace énfasis en el reconocimiento de las capacidades locales, entendiendo que son estas las que conviven en el territorio, realizan intercambios, conocen sus dinámicas y quienes mejor han apropiado la zona. Asimismo, se tiene en cuenta la importancia medioambiental del territorio de estudio y se busca evitar un efecto negativo en el balance de la zona de reserva, ante la indefinición de políticas y de sus usos concretos. Por último, se señala que el problema traspasa la cuestión de la soberanía y está más vinculado a la definición de mecanismos de cooperación e integración entre los Estados. Para ello, se establece un diálogo entre la teoría de bienes comunes de Elinor Ostrom (2000) y la teoría de los regímenes internacionales desde su perspectiva más neoliberal, buscando una salida a varios de los problemas que subyacen al planteamiento. El primero está vinculado a la indeterminación del bien común, en términos de su extensión, unidad, usos y las normas para su protección. Seguidamente, la definición del manejo de esta zona debe estar atada más a la cooperación que al conflicto, de modo que permita tener una mayor consciencia de las ganancias futuras de una buena admi- nistración conjunta del territorio, por encima de las ganancias relativas de una actuación unilateral de los Estados. La cooperación entre Estados para la edificación de normas, formales o no, debe ser orientada, no obstante, por las poblaciones locales que son quienes tienen el conocimiento de los usos y los cuidados de una zona de interés global, pero con incidencia local.

Lo anterior se hace buscando entender que la alternativa más idónea para la protección de un espacio medioambiental como la Reserva de Biósfera Seaflower, en un escenario de indeterminación y conflicto, es la generación de mecanismos institucionales formales y no formales, construidos desde las poblaciones locales que responden a una afinidad sociocultural y se mueven en un ambiente favorable para el logro de mecanismos de integración y cooperación "desde abajo", en los que los Estados sean gestores y garantes de los acuerdos, más que quienes definen y ejecutan las formas de administración del territorio.

\section{El marco de los "comunes" y la necesidad de construir regímenes internacionales}

Para esta investigación, se ha tenido en cuenta el desarrollo teórico sobre los "comunes" realizado por Elinor Ostrom en El Gobierno de los Bienes Comunes (2000), por su pertinencia para la comprensión los recursos de uso común (RUC). También se ha puesto esta teoría en diálogo con las teorías de regímenes internacionales en el ámbito 
de las relaciones internacionales, para ampliar el alcance de la teoría, pues sus análisis son en principio meramente locales. Con ello la hemos llevado a un ámbito de comprensión de una situación transfronteriza donde hay una perspectiva local y, a su vez, de articulación regional.

\section{El manejo de los comunes en la teoría de Ostrom}

En un intento por dar respuesta a los problemas vinculados a la acción colectiva con respecto al uso de RUC, Ostrom construye un cuerpo teórico alternativo a las dos formas tradicionales en que se ha concebido su manejo. Los acercamientos referentes a la acción colectiva en RUC han desembocado en la ya conocida "tragedia de los comunes" (Hardin, 1968), resultado inevitable de la acción racional de los individuos en búsqueda de la maximización de un recurso escaso. Esto lleva al recurso al agotamiento o al sobreúso.

Pero antes de ver cómo resuelve la autora esa "tragedia", es necesario precisar algunos elementos conceptuales. En primera instancia, debe comprenderse a los RUC como "un sistema de recursos naturales [...] lo suficientemente grande como para volver costoso excluir a destinatarios potenciales de su uso" (Ostrom, 2000, p. 66). Este tiene dos aristas, su sistema de recursos, el cual refiere a la composición física y acervo del espacio, con lo cual se puede entender la estructura de capacidad y los posibles recursos que reposan en él. Por otro lado, la unidad de recursos se refiere al funcionamiento junto con las cantidades de apropiación posibles en el sistema, es decir las cantidades realmente existentes.

Quienes interactúan con el RUC son tanto los apropiadores como los proveedores. En este trabajo, interesa concentrarse en los primeros, es decir quienes lo usan y recogen unidades de recurso y conocen el funcionamiento del sistema de recursos. Con estos elementos, el RUC se enfrenta a la dificultad del congestionamiento y la sobreutilización por parte de los apropiadores, en un escenario de indeterminación de acuerdos sobre el manejo del sistema (Ostrom, 2000, p. 69).

En el escenario de estudio, se presentan los dos problemas mencionados, ante las actuaciones individuales de los apropiadores, que no tienen en cuenta su situación de interdependencia, puesto que el sistema de recursos los vincula inevitablemente y el exceso de apropiación tiene un efecto negativo directo entre todos ${ }^{2}$. Una actuación racional individual, resulta en ganancias mínimas, visto a través de la interdependencia entre los actores, lo que no sucedería actuando de manera coordinada (Ostrom 2000, p. 77). Con esto, se puede entender que un

2 Aquí se puede hacer referencia al llamado "Dilema del prisionero", según el cual la cooperación o deserción del uno tiene incidencia en el otro y donde actúan de manera individual, pensando en el beneficio propio, a pesar de la interdependencia. 
colapso de recursos en un sistema socioecológico se da por apropiaciones que no se comunican y la falla en el desarrollo de reglas y normas de manejo (Ostrom, 2009).

Por lo anterior, es vital comprender que la cooperación es deseable para: 1) lograr ganancias mayores a las que podrían obtenerse en una actuación individual no cooperativa y 2) mantener el sistema de recursos, lo que permitiría la reproducción de unidades de recurso a largo plazo y evita el sobreúso.

Ostrom entra en debate con las concepciones tradicionales de acción colectiva, basadas en actuaciones racionales que desembocan en la mencionada "tragedia de los comunes". Las soluciones propuestas para la resolución del problema se han establecido a través de vías Estatales de control y coerción o de vías de mercado, privatizadoras $^{3}$. Al respecto, Ostrom (2000, p. 35) afirma que "se concluye que los individuos están atrapados en una trampa siniestra" y que "las recomendaciones políticas resultantes también han tenido una índole igualmente siniestra", entendiendo que ambas salidas resultan insuficientes y no llevan necesariamente a la cooperación, debido a los costos que implica un sistema de información, control y sanción estatal y la dificultad resultante de la definición de límites de propiedad por la incapacidad de repartir el recurso de manera justa o adecuada.

Por ello, Ostrom (2000) apunta a "dejar de ver a los usuarios de los recursos naturales como prisioneros", con lo cual deben incrementarse las capacidades de los participantes para definir los parámetros de la acción y manejo de los RUC, buscando tanto resultados distintos a las tragedias implícitas en actuaciones racionales como formas de coordinación de la acción colectiva de forma externalizada.

No debe perderse de vista que este trabajo trata sobre un RUC indefinido, pues su jurisdicción, en relación con la soberanía, no está definida y porque el conflicto de límites entre los Estados genera un alto nivel de incertidumbre y una intersección de normas. Esto, a su vez, hace que los usos puedan ser conflictivos, lo cual pone en riesgo al medio. Los actores son en cierta medida prisioneros de dicha indeterminación y una apuesta a sacarlos de esta prisión es lograr acuerdos más allá de la frontera, que respondan a sus intereses, usos y formas de organización.

Para ello, Ostrom entiende que las formas de cooperación se producen en las comunidades que conviven con el

3 En la primera solución, se dice que el control del recurso debe ser establecido por una autoridad que logre fundamentar un sistema de sanciones, que determine un conjunto de normas que eviten el sobreuso y el gorroneo (free-riders) del recurso. La segunda establece la determinación de unos sistemas de propiedad con los cuales se evita el acceso indiscriminado al recurso y se limitan las zonas donde un individuo puede explotarlo. 
RUC y alrededor del RUC mismo. A diferencia de los dos modelos tradicionales, en este caso, no se impone un contrato externo sino que nace en el seno de los individuos y la actuación probable de un actor exógeno está más vinculada con regulación y acompañamiento del contrato, sin tener en cuenta si es formal o no.

Pero ipor qué es más pertinente esta vía? Para Ostrom (2000, p. 46) son los individuos los que tienen la información "a la mano", debido a su familiaridad y cercanía con el RUC con respecto a sus usos y a la caracterización de los actores, con lo cual reducirían los costos derivados de la búsqueda de una solución externa y, además, se haría una utilización más "eficiente" del recurso, manteniendo el equilibrio del sistema.

Las condiciones para lograr estas formas autoorganizadas son la construcción de unas exigencias propias, edificación de formas variadas de acción y de resolución de conflictos, derechos comunes y cooperación junto con la solidaridad. Además, deben establecerse reglas claras y pertinentes sobre la apropiación, las formas de uso, la cooperación, la restricción, el aprovisionamiento y la distribución del RUC (Añaños, 2014, pp. 160-161).

Con todo lo anterior, puede desembocarse, finalmente, en un bien común que, de acuerdo con Añaños (2014) responde a
[...] la existencia de un régimen autónomo de regulación, que es un proceso social complejo con exigencias propias y formas variadas que dependen, sobre todo, de la naturaleza del recurso, pero también de la constitución de la comunidad de usuarios y de sus instituciones, los mismos que dan lugar a derechos comunes de sus usuarios en una relación de cooperación y solidaridad - puesto que- no existen bienes comunes sin un acuerdo previo entre los usuarios o propietarios en el cual reglamentan su adquisición, uso y distribución para beneficio de todos y cada uno de ellos. (p. 160)

Pero, como el interés de Ostrom está vinculado sobre todo a los bienes de carácter local, debe darse un diálogo con aspectos vinculados a las relaciones internacionales, para lo cual se debe incluir la teoría de los regímenes internacionales y la edificación de instituciones de carácter internacional o transfronterizas, que reduzcan el conflicto y potencien la cooperación.

\section{Inclusión de los regímenes internacionales}

Lo primero que hay que identificar es el sentido de los regímenes internacionales, los cuales entendemos como "conjunto de principios, normas, reglas y procedimientos para la toma de decisiones que rige el comportamiento de los Estados en un área de la política internacional" (Hasenclever, Mayer y Rittberger, 1999, p. 499), y que explican la posible coo- 
peración entre los Estados en ámbitos de la política mundial.

Dichos regímenes pueden tomar formas institucionales ya sean formales o informales, en el mismo sentido en el que se da con Ostrom y con estas se busca establecer unos papeles de conducta, una configuración de expectativas, ser transmisoras de la información, tener incidencia en los incentivos y los costos (Keohane, 1993). En sí, no estamos hablando de organismos establecidos con normas concretas, sino que también pueden ser acuerdos entre Estados que no generan institucionalidad o convenciones de acción internacional implícitas ${ }^{4}$.

El estudio de los regímenes internacionales, en su acepción tradicional, se ha hecho desde las escuelas clásicas de las relaciones internacionales. Es de interés para este trabajo la visión neoliberal de éstos, ya que responden a lo planteado previamente por Ostrom, pero a una perspectiva ampliada al ámbito internacional. Aquí, la percepción de la cooperación sobre el conflicto o la maximización está vinculada a la capacidad de que los Estados puedan lograr un beneficio mutuo, con lo que, al mismo tiempo, disminuye la asimetría en términos de información o fuerza. No se trata de una visión altruista, pues, de hecho, parte del racionalismo clásico de la maximización, como en Ostrom, pero hay una comprensión de cual la cooperación podría desembocar en un subóptimo más benéfico que la acción unilateral (Hasenclever et al., 1999; Keohane, 1993).

Pero la perspectiva altamente estatocéntrica requiere ser problematizada para que tenga asidero en esta propuesta de investigación. El estudio de regímenes nació en medio de los debates de la década de 1970, en medio de la recomposición del sistema internacional y de la Guerra fría con un alto protagonismo del Estado-nación. Pero su rango de análisis concentrado en los Estados debe ser revaluado. Strange (2009), entre las cinco críticas que hace a la teoría de regímenes, apunta acertadamente a demostrar que muchas de las negociaciones de regímenes están atravesadas por intereses particulares dentro de los Estadosnación y que los grupos de presión tienen incidencia en su construcción. No son los Estados los que llevan el desarrollo de los regímenes y sus instituciones, sino existen otros niveles en donde la negociación tiene cabida y allí también se tejen otras dinámicas que se salen de control del Estado.

4 En el sistema internacional existe gran variedad de regímenes que configuran o no instituciones y uno de esos es el del medio ambiente, relevante en este caso. Todos los regímenes alrededor de la problemática del cambio climático y de la reducción de emisiones han estado vinculados a una serie de principios establecidos en las distintas Cumbres de Rio, los Protocolos de Kyoto y, más recientemente, en la Cumbre de París sobre la materia. Aunque no se configuran como instituciones, los Objetivos de Desarrollo Sostenible son una buena forma de ejemplificar un régimen internacional, como un conjunto de orientaciones y búsqueda de resultados que los Estados intentan alcanzar colectivamente, frente a un problema global. 
Por ello, autores como Grasa (2001) y Peña Medina (2011) apuntan a hacer un aporte conceptual desde otros niveles y agendas "menores" que implican una visión transfronteriza de los regímenes internacionales. El primero amplía la construcción de los regímenes incluyendo "actores internacionales o actores con vocación internacional", los cuales "influyen de manera decisiva en los procesos de elaboración y, por ende, en los rasgos definitorios e instrumentos de numerosas políticas medioambientales de ámbito interno" (Grasa, 2001, p. 114). Esta afirmación supone que los regímenes también tienen una visión transnacional, vinculada con la aparición de sociedad civil y actores no estatales, con lo cual se explica el linkage entre los distintos actores del sistema internacional al momento de comprender los regímenes. Así, estos no se dan "desde arriba", sino que están imbricados en una serie de necesidades y presiones de actores que tienen agendas propias y plantean demandas internamente.

Con lo anterior, el segundo de los autores empieza por concebir la frontera como un espacio relacional, al decir de David Harvey, para mostrar que cualquier tipo de régimen expresado en planificación transfronteriza debe sustentarse en comunicación entre los actores fronterizos y la formación de redes, entendiendo que una visión a la frontera desde esta perspectiva rompe jerarquías y amplía espacios de debate y decisión (Peña Medina, 2011). Con ello "la necesidad de crear un régimen para evitar la tragedia de los comunes es evidente. El establecimiento de mecanismos de decisión colectiva para manejar recursos naturales comunes es un dilema trasversal o general en todas las fronteras" (Peña Medina, 2011, pp. 121-122) y, para el caso de interés de este artículo, estamos de cara a un recurso de vital importancia que ha quedado en una indeterminación fronteriza que requiere claramente de una institucionalidad basada en regímenes, que vayan más allá de una mera coordinación interestatal.

\section{Las reservas de biósfera transfronterizas (RBT) en el escenario internacional}

Entre los programas que ha desarrollado la UNESCO, en correspondencia con toda la oleada de acuerdos, cumbres y tratados vinculados a la preservación del medio ambiente, se encuentra el del Hombre y la Biósfera (MAB). En la década de 1970, la institución encontró un reemplazante al casi extinto Programa Biológico Internacional (IBP, por sus siglas en inglés) y estableció como su objetivo ser "un programa de investigación interdisciplinario que enfatiza en el enfoque ecológico del estudio de las interrelaciones del hombre con su ambiente" (UNESCO, 1972, como se cita en Valencia, 1987).

La UNESCO es quien estipula las zonas que pueden ser determinadas como reservas de biósfera, las cuales se articulan con la Red Mundial de Reservas de Biósfera, apoyada en una estructura de redes regionales y subregionales (PoolStanvliet, 2013, p. 1). Para las zonas 
determinadas como Reservas, se han establecido recomendaciones y metas que están plasmadas en la Estrategia de Sevilla de 1995, su Marco Estatutario complementado por varias declaraciones y el Plan de Acción de Madrid.

Las tres funciones principales de una reserva están vinculadas a la conservación, el desarrollo sostenible y el apoyo logístico, como investigación o educación (Pool-Stanvliet, 2013, p. 1) $y$, al aproximarse a los principios de la Estrategia de Sevilla, se ve cómo este programa de reservas está articulado a los regímenes internacionales del medio ambiente, como las cumbres de Rio, el Programa 21 y los acuerdos sobre la diversidad biológica y el medio ambiente sustentable.

La Estrategia, además, tiene un amplio interés por la participación de los pobladores en la conformación del espacio de la reserva. Esto es claro cuando afirma que la estrategia debe permitir que "las comunidades locales participen plenamente en la conservación y uso sostenible de los recursos", también cuando afirma que deben buscar "un equilibrio sostenible entre las necesidades, a veces en conflicto, la conservación de la diversidad biológica, fomentar el desarrollo económico y conservar los valores culturales a este vinculados" (Resolución 28 c/2.4, 1995, sin énfasis en el original). Esto es vital porque amplía la concepción de las reservas, al considerar también a quienes las habitan y las usan.

Sumado a esto, las directrices 8 y 9 de la Estrategia van encaminadas a dar un papel de empoderamiento a quienes cohabitan en la reserva. Por ello afirma que se debe

[...] propiciar la administración a cada reserva de biósfera esencialmente como un «pacto» entre la comunidad local y la sociedad en su conjunto. La administración debe ser más abierta, evolutiva y adaptativa. Este enfoque permitirá asegurar a la reserva y a sus comunidades locales mejores condiciones para responder a las presiones externas de índole política, económica y social y agrupar a todos los sectores interesados en una tarea común que permita promover las reservas de biósfera en el plano local y en las redes. La información debe circular libremente entre todas las partes involucrada. (Resolución 28 c/2.4, 1995)

Se entiende que las Reservas son "zonas de ecosistemas terrestres o costeros-marinos, o una combinación de ellos, reconocidos en el plano internacional" (Resolución 28 c/2.4 1995) y, para que exista este reconocimiento, la zona debe cumplir con unas características concretas, como tener: 1) una o más zonas núcleo, 2) una zona tampón 
y 3) una zona de transición flexible (o área de cooperación) ${ }^{5}$.

Lo anterior está establecido en el Marco Estatutario donde, además, se exige que exista claridad en aspectos referidos a las formas organizativas para la participación de los distintos actores involucrados, un plan de gestión, claridad en los programas de investigación y capacitación. La designación se da por parte del Consejo Internacional de Coordinación (CIC) ante solicitudes nacionales y también dicho consejo ejecutará la evaluación periódica cada diez años.
En la Estrategia se definen diversos objetivos y se establecen algunos indicadores/recomendaciones para el buen funcionamiento de las reservas. En la tabla 1 se listan algunos de los indicadores de relevancia para este trabajo, que muestran la posibilidad efectiva de una alta participación de las poblaciones locales y da cuenta de la importancia de lograr una visión transfronteriza de las reservas. Dado que no existe, necesariamente, una correspondencia entre las fronteras políticas y las ambientales, la UNESCO también se ha referido a las Reservas de Biósfera Transfronterizas (RBT).

Tabla 1. Recomendaciones en los tres ámbitos de acción de la Estrategia de Sevilla referentes a participación local, institucionalidad y articulación con los regímenes internacionales del medio ambiente.

\begin{tabular}{|c|l|}
\hline Ámbito & \multicolumn{1}{c|}{ Recomendaciones } \\
\hline \multirow{5}{*}{ Internacional } & $\begin{array}{l}\text { Promover las reservas de biósfera como un medio para la realización de los objetivos del } \\
\text { convenio de la diversidad biológica. }\end{array}$ \\
\cline { 2 - 3 } & $\begin{array}{l}\text { Fomentar el establecimiento de RBT como medio de conservación de organismos, } \\
\text { ecosistemas, recursos genéticos que traspasan las fronteras nacionales. }\end{array}$ \\
\cline { 2 - 3 } & $\begin{array}{l}\text { Preparar orientaciones sobre los problemas esenciales de la administración de las reservas } \\
\text { de biósfera, por ejemplo, sobre la solución de conflictos, la concesión de beneficios en el } \\
\text { plano local y la participación de las partes interesadas en la adopción de decisiones y la } \\
\text { responsabilidad de la administración. }\end{array}$ \\
\cline { 2 - 2 } & $\begin{array}{l}\text { Facilitar el intercambio de experiencias e información entre reservas de biósfera con miras } \\
\text { a fortalecer la participación de voluntarios y de las comunidades locales en las actividades } \\
\text { de reserva de biósfera. }\end{array}$ \\
\cline { 2 - 3 } & $\begin{array}{l}\text { Preparar directrices sobre asuntos de administración en las reservas de biósfera incluidos, } \\
\text { entre otras cosas, métodos de obtener la participación local, monografías sobre diversas } \\
\text { opciones de gestión y técnica de solución de conflictos. }\end{array}$ \\
\cline { 2 - 2 } & $\begin{array}{l}\text { Promover y facilitar el hermanamiento entre reservas de biósfera y propiciar la creación de } \\
\text { reservas transfronterizas. }\end{array}$ \\
\hline
\end{tabular}

5 Basados en la Estrategia de Sevilla (Resolución 28 c/2.4 1995), las características podrían definirse, así: 1) zonas núcleo: son beneficiarias de protección a largo plazo, conservan la diversidad biológica, son espacios donde se realizan actividades poco perturbadoras; 2) zona tampón, es circundante o colindante con la zona núcleo, aquí se realizan actividades cooperativas compatibles con prácticas ecológicas como la educación sobre el medio ambiente, recreación, turismo e investigación; 3) zona de transición, donde pueden darse actividades de apropiación de recursos vivos, debe tener una gestión conjunta de administración para el desarrollo sostenible por los implicados en la reserva. 


\begin{tabular}{|c|c|}
\hline \multirow{2}{*}{ Nacional } & $\begin{array}{l}\text { Velar porque cada reserva de biósfera tenga una política o un plan de administración } \\
\text { operacional y tenga una autoridad o un mecanismo para aplicarlos. }\end{array}$ \\
\hline & $\begin{array}{l}\text { Promover y facilitar el hermanamiento entre reservas de biósfera y propiciar la creación de } \\
\text { reservas transfronterizas. }\end{array}$ \\
\hline \multirow{11}{*}{ Local } & $\begin{array}{l}\text { Determinar cuáles son los intereses de las diferentes partes interesadas e integrarlas a los } \\
\text { procesos de planificación y adopción de decisiones en la administración y utilización de la } \\
\text { reserva de biósfera }\end{array}$ \\
\hline & $\begin{array}{l}\text { Determinar los factores que contribuyen al deterioro del medio ambiente, a la utilización } \\
\text { no sostenible de los recursos biológicos y tomar las medidas correspondientes. }\end{array}$ \\
\hline & $\begin{array}{l}\text { Realizar una evaluación de los productos naturales y los servicios de la reserva y, sobre } \\
\text { esta base, promover medios ecológicamente sanos y económicamente viables de extraer } \\
\text { beneficios para las poblaciones locales. }\end{array}$ \\
\hline & $\begin{array}{l}\text { Crear incentivos para la conservación y el uso sostenible de los recursos naturales y fuentes } \\
\text { sustitutivas de ingresos para las poblaciones del lugar. }\end{array}$ \\
\hline & $\begin{array}{l}\text { Garantizar que los beneficios obtenidos gracias a la explotación de los recursos naturales } \\
\text { se distribuyan equitativamente entre las partes interesadas mediante, por ejemplo, la } \\
\text { distribución de los derechos percibidos por concepto de admisión, venta de productos } \\
\text { naturales o artesanales, utilización de técnicas de construcción, programas y actividades de } \\
\text { la reserva de la biósfera. }\end{array}$ \\
\hline & $\begin{array}{l}\text { Establecer una estructura consultiva local que represente a los copartícipes económicos y } \\
\text { sociales, inclusive todos los intereses. }\end{array}$ \\
\hline & $\begin{array}{l}\text { Organizar foros y establecer sitios de demostración para estudiar los problemas } \\
\text { socioeconómicos y ambientales de la región y para el uso sostenible de los recursos } \\
\text { biológicos de importancia para la región. }\end{array}$ \\
\hline & $\begin{array}{l}\text { Propiciar formaciones apropiadas y el empleo de las comunidades locales y otros agentes } \\
\text { de modo que puedan participar plenamente en el planteamiento, la administración, los } \\
\text { sistemas de observación de la reserva de biósfera. }\end{array}$ \\
\hline & $\begin{array}{l}\text { Elaborar, aplicar y seguir un plan o una política de ordenación para el conjunto de las } \\
\text { reservas con sus diferentes zonas. }\end{array}$ \\
\hline & $\begin{array}{l}\text { Concebir y establecer mecanismos institucionales para administrar, coordinar e integrar los } \\
\text { programas y las actividades de la reserva. }\end{array}$ \\
\hline & $\begin{array}{l}\text { Cuidar que las comunidades locales participen en el planteamiento y la administración de } \\
\text { la reserva. }\end{array}$ \\
\hline
\end{tabular}

Fuente: Elaboración propia con base en (Resolución 28 c/2.4 1995).

\section{Sevilla +5 y las recomendaciones para ámbitos transfronterizos}

En el documento de noviembre de 2000 , se establecen algunas recomendaciones para el buen funcionamiento de Reservas de Biósfera que se desfasan de los límites nacionales. Aquí, se dice que una RBT es "el reconoci- miento oficial a nivel internacional de la voluntad política de cooperar en la conservación y uso sostenible a través de una gestión común de un ecosistema compartido" (UNESCO, 2000), al ser espacios en los cuales debe existir un cierto nivel de flexibilidad en su configuración. 
Así, se establecen algunas recomendaciones, que se muestran en la tabla 2, clasificadas ya sea para el establecimiento, el funcionamiento o los mecanismos institucionales. En ellas, destacan la necesidad de la voluntad política por parte de las autoridades nacionales de los países, la identificación clara de los actores, modos de acción claros y armonizados y una coordinación bien definida que permita llevar a buen puerto la reserva transfronteriza.

Tabla 2. Recomendaciones para el establecimiento, el funcionamiento y los mecanismos institucionales de las RBT. Recomendaciones de Sevilla +5 para la operación de las RBT.

\begin{tabular}{|c|c|c|}
\hline \multicolumn{3}{|c|}{ Recomendaciones para el establecimiento, el funcionamiento y los mecanismos institucionales de las RBT } \\
\hline Establecimiento & Funcionamiento & Mecanismos institucionales \\
\hline $\begin{array}{l}\text { Establecer una RBT a cada } \\
\text { lado de la frontera o } \\
\text { definir la zonificación del } \\
\text { área según los criterios } \\
\text { generales de designación } \\
\text { de RB. }\end{array}$ & $\begin{array}{l}\text { Tener un plan de } \\
\text { zonificación adecuado, } \\
\text { comprensión común de } \\
\text { las características de cada } \\
\text { zona y medidas de gestión } \\
\text { similares. }\end{array}$ & $\begin{array}{l}\text { La estructura de coordinación es representativa } \\
\text { de diversas administraciones y consejos } \\
\text { científicos, así como las autoridades encargadas } \\
\text { de las zonas protegidas, los representantes de } \\
\text { las comunidades locales, los grupos interesados } \\
\text { o afectados, incluyendo a la juventud y al sector } \\
\text { privado. }\end{array}$ \\
\hline $\begin{array}{l}\text { Identificar a los socios } \\
\text { locales y nacionales y } \\
\text { establecer un grupo de } \\
\text { trabajo para definir bases } \\
\text { e identificar los temas } \\
\text { claves de cooperación. }\end{array}$ & $\begin{array}{l}\text { Mapa conjunto de } \\
\text { zonificación. }\end{array}$ & $\begin{array}{l}\text { El sector de ONG de la zona estará representado } \\
\text { en la estructura. }\end{array}$ \\
\hline $\begin{array}{l}\text { Firmar un acuerdo oficial } \\
\text { entre las autoridades } \\
\text { gubernamentales respecto } \\
\text { a la RBT. }\end{array}$ & $\begin{array}{l}\text { Definición de objetivos, } \\
\text { medidas comunes, plan } \\
\text { de trabajo, presupuesto, } \\
\text { inclusión en lista de metas } \\
\text { de la estrategia de Sevilla. }\end{array}$ & $\begin{array}{l}\text { Esta estructura tiene una secretaría permanente } \\
\text { y un presupuesto que se dedica a su } \\
\text { funcionamiento. }\end{array}$ \\
\hline $\begin{array}{l}\text { Las autoridades estatales } \\
\text { respectivas nominarán } \\
\text { a las diversas partes } \\
\text { indicaciones acerca } \\
\text { de los componentes } \\
\text { principales de un plan de } \\
\text { cooperación futuro. }\end{array}$ & $\begin{array}{l}\text { Identificación de fuentes } \\
\text { de financiación, búsqueda } \\
\text { simultánea o conjunta de } \\
\text { las mismas. }\end{array}$ & $\begin{array}{l}\text { Se designa una persona a cada uno de los } \\
\text { lados para actuar como grupo focal de la } \\
\text { cooperación. }\end{array}$ \\
\hline \multirow{3}{*}{$\begin{array}{l}\text { Se da una designación } \\
\text { oficial del Consejo } \\
\text { Internacional de } \\
\text { Coordinación (CIC) }\end{array}$} & $\begin{array}{l}\text { Dotación de estructuras de } \\
\text { gestión armonizadas. }\end{array}$ & $\begin{array}{l}\text { Las reuniones generales de la coordinación } \\
\text { estarán complementadas por grupos temáticos } \\
\text { sobre una base ad hoc para crear una } \\
\text { plataforma de debate entre los agentes de los } \\
\text { países implicados, con intención de promover } \\
\text { todas las oportunidades que se presenten para } \\
\text { intercambiar opiniones y conocimientos. }\end{array}$ \\
\hline & \multirow{2}{*}{$\begin{array}{l}\text { Medios de comunicación } \\
\text { claros y definidos por las } \\
\text { partes. }\end{array}$} & $\begin{array}{l}\text { Los equipos conjuntos de personal son } \\
\text { operativos para tareas específicas. }\end{array}$ \\
\hline & & $\begin{array}{l}\text { Se organiza una asociación con el objetivo } \\
\text { específico de promover las RBT. }\end{array}$ \\
\hline
\end{tabular}

Fuente: elaboración propia con base en UNESCO (2000). 
Existe una amplia comprensión alrededor de la importancia de la coordinación en espacios escindidos por fronteras nacionales, pero que conservan una unidad ambiental. Al leerse las recomendaciones, se puede dar cuenta de la importancia que se da a los ejercicios de cooperación, planeación conjunta, información de ambas partes y objetivos comunes. Aunque también es notorio que existe las instancias gubernamentales más institucionalizadas son muy importantes.

Dentro de los indicadores de gestión, son claras las recomendaciones para evitar el "gorroneo", la búsqueda de políticas comunes para el mantenimiento y la rehabilitación, así como la consolidación de incentivos para el logro de alternativas viables. Además, es claro el mandato para la búsqueda de participación de las comunidades locales y sus formas de asociación que se acompasen con el arreglo institucional sin dejar de lado el fomento de intercambios e impulso a los acontecimientos culturales que fortalezcan y preserven el patrimonio cultural e histórico.

Con lo anterior, vemos que hay un amplio interés por evitar un sobreúso o mal uso de los recursos naturales en espacios de equilibrio ecológico y ambiental. Se ha explicado que el caso de la Reserva de Biósfera Seaflower se encuentra en una indeterminación ante unos límites vagamente definidos y una tensión por el uso del espacio marítimo por parte de los dos países que ahora comparten soberanía sobre la reserva y, para ello, es vital encontrar mecanismos de coordinación, trabajo conjunto y comunicación fluida pero el conflicto a nivel de los Estados nos invita a revisar desde otra óptica las formas de consolidación de una RBT en la zona donde la base histórico-cultural y el conocimiento y cohabitación con el espacio son fortalezas para explotar en una búsqueda de acuerdos desde el nivel local. Pero iexisten acuerdos desde el ámbito de lo local para la configuración de una RBT? Vale la pena revisar dos casos de Reservas ya consolidadas en donde veremos cómo es su funcionamiento y las lecciones que pueden ser aprendidas de ambas.

\section{Reserva de Biósfera Intercontinental del Mediterráneo y el trifinio fraternidad: una mirada a dos reservas de biósfera transfronterizas}

Hacer una propuesta para la edificación de una Reserva de Biósfera Transfronteriza implica la revisión de las ya existentes, con el objetivo de ver sus propias dinámicas de funcionamiento que sirvan como aporte para la consolidación de una RBT en el Gran Caribe. Se han tomado como referencia dos Reservas como lo son la Reserva de Biósfera Intercontinental del Mediterráneo (RBIM) entre España y Marruecos (figura 1) y la Reserva del Trifinio Fraternidad entre Guatemala, Honduras y El Salvador. El primero de los dos casos se tomó a partir de las similitudes que tiene con el caso que interesa a este artículo, es decir, una disputa limítrofe, un territorio marítimo (maritorio) indefinido y conflictos entre 
ambos Estados. El segundo se tuvo en cuenta ante las particularidades del contexto latinoamericano y, más exactamente centroamericano; y por estar vinculado a una visión altamente soberanista de las fronteras. En ambos casos, se tendrán en cuenta tanto los arreglos institucionales que tienen las RBT, como los recursos en juego y la participación de los actores locales.

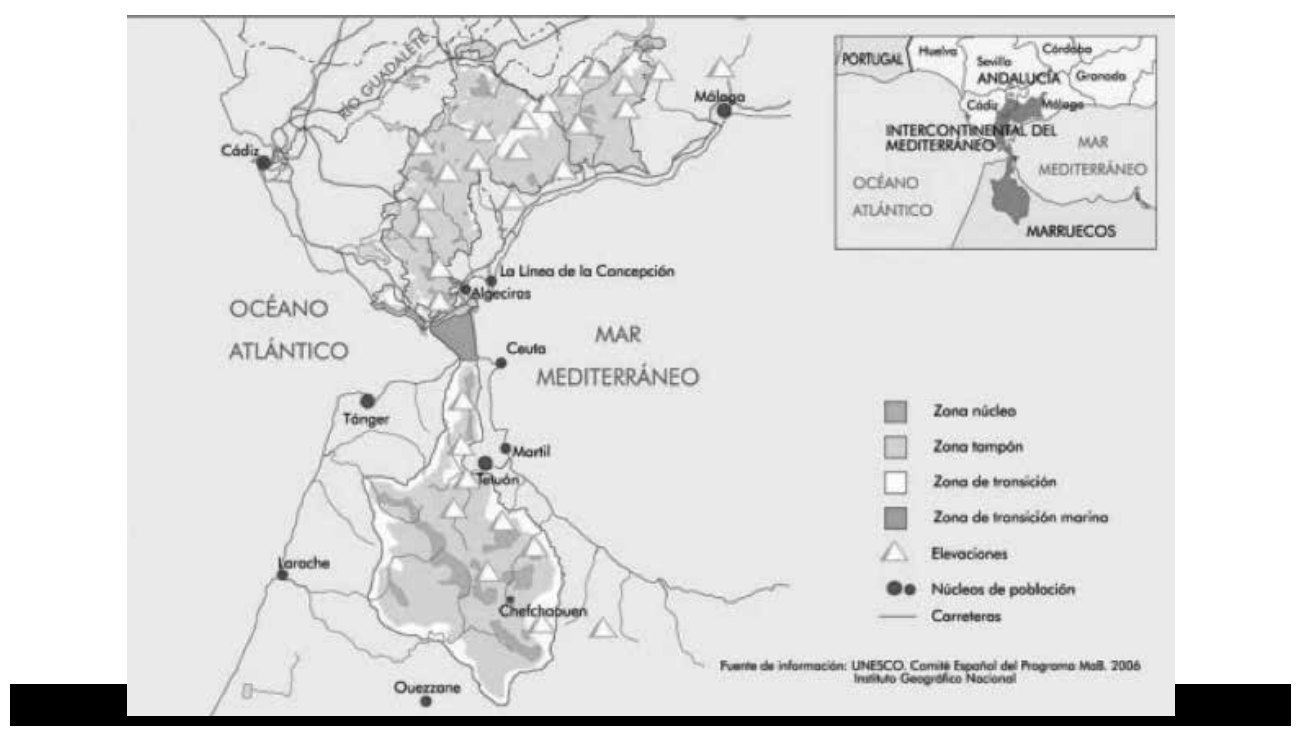

Figura 1. Definición de las zonas, según clasificación de la UNESCO, en la región de Gibraltar, entre España y Marruecos, para la conformación de la RBIM. Fuente: mapa tomado de http://rerb.oapn.es/index.php/redespanola-de-reservas-de-la-biósfera/las-reservas-de-la-biósfera-espanolas/1-2-1-mapa/intercontinental-delmediterraneo/ficha-de-la-reserva

Por un lado, en la región del Estrecho de Gibraltar, se encuentra una región ecológica separada por el Mar Mediterráneo, compartida por España y Marruecos. Allí se estableció la zona de reserva de biósfera. Aunque que no está exenta de problemas, constituye un gran aporte para la conservación ecológica y la resolución de conflictos regionales.

En este espacio "se manifiestan tensiones derivadas de las cuestiones territoriales sobre las ciudades y las plazas españolas en el norte de África, pero también, y derivado del anterior, la ausencia de delimitación de los espacios marítimos" (Verdú-Baeza, 2012, p. 398). Todo esto, vinculado a los reclamos marroquíes sobre los enclaves españoles de Ceuta y Melilla, los peñones adyacentes a estas, las Islas Canarias, el tema migratorio, la definición de ejercicios de pesca y otros elementos de seguridad, todo lo cual que ha llevado a que la relación bilateral fluctúe entre la cooperación y el conflicto (Iglesias, 2010, p. 20). 
Un hecho clave ocurrió en el periodo 2001-2003. Se trata de la ocupación marroquí del islote Perejil, el cual se dio en medio de un ambiente viciado, alrededor de varios temas de interés para ambos Estados y sobre los cuales no se generó diálogo alguno. Lo anterior conllevó casi a la ruptura diplomática entre los Estados. Sin embargo, el conflicto fue saneado con la participación de Colin Powell, secretario de Estado de Estados Unidos (De Larramendi, 2003).

Para Verdú-Baeza (2012) es en este contexto entre ambos Estados que recientemente pudo surgir

[...] un mecanismo de cooperación transfronteriza, sumamente original e innovador en torno al medio ambiente que va a configurarse como un factor de dinamización de las relaciones entre Andalucía y el norte de Marruecos, y un factor sobre el que pivotará un conjunto de actuaciones dirigidas no sólo a la conservación de los ricos y valiosos ecosistemas que se encuentran en la zona, sino también a la dinamización de las economías locales sobre un modelo de desarrollo sostenible. (p. 399)

En cuanto a Latinoamérica, una de las experiencias más exitosas conocidas en materia de cooperación transfronteriza es el Plan Trifinio (Hirezi, 2012; Conato, 2009), donde se encuentra ubicada la Reserva de Biósfera Transfronteriza Trifinio Fraternidad (figura 2).

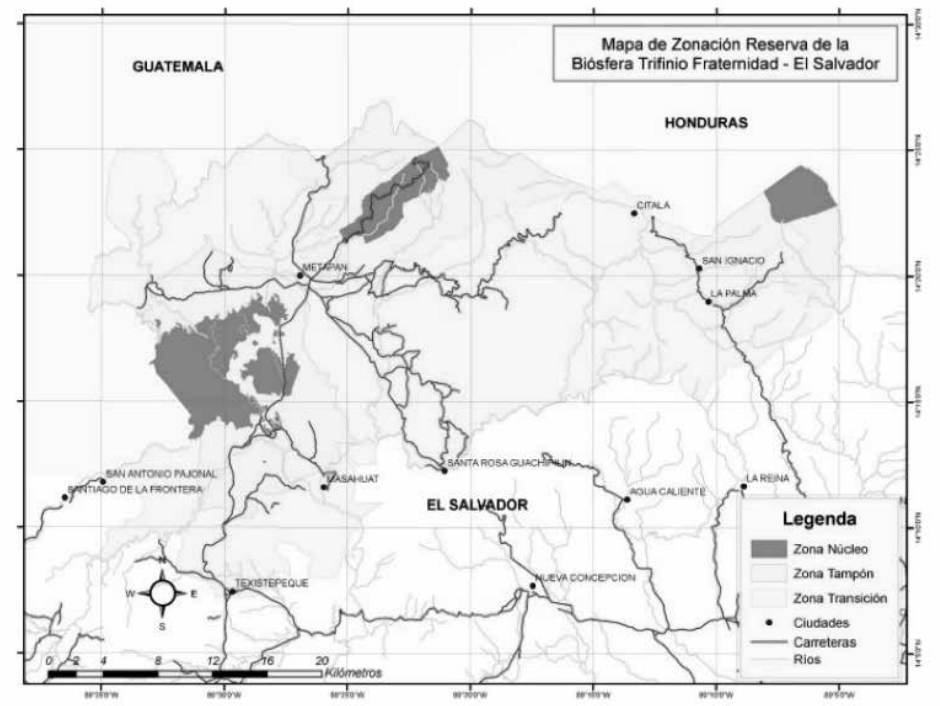

Figura 2. Mapa de la reserva de biósfera Trifinio Fraternidad. Fuente: tomado de http://oficinaterritorial. blogspot.com.co/ 
Definida por un tratado firmado por Honduras, Guatemala y El Salvador, la reserva es una zona de $7241 \mathrm{~km}^{2} \mathrm{com}$ partida por los tres países. Guatemala y Honduras cuentan con la mayor parte, mientras que El Salvador apenas posee el $15 \%$ de la zona (Conato 2009, p. 133). En el Trifinio se encuentran 45 municipios de los tres países que comparten la zona fronteriza. Es un lugar donde se vive de manera muy fuerte el fenómeno de hibridación fronteriza, vinculado a la historia del asentamiento de los Maya Chortí; es además un lugar de una alta dependencia de los recursos existentes en la zona, particularmente de los hídricos (Artiga, s. f.; Task Team on South South Cooperation, 2011).

En la tabla 3 se realiza un ejercicio comparado entre ambas experiencias en donde se recogen los elementos ya mencionados previamente para el análisis comparado. En una revisión breve, variable por variable, los aspectos más importantes de ambas experiencias y que son de interés para la propuesta que aquí se va a edificar se presentarán a continuación.

Tabla 3. Análisis comparado de las reservas de biósfera transfronterizas propuestas comparación de las variables de los casos seleccionados.

\begin{tabular}{|c|c|c|c|}
\hline $\begin{array}{c}\text { Reserva de } \\
\text { biósfera } \\
\text { transfronteriza }\end{array}$ & Sistema de recursos & Arreglos institucionales & $\begin{array}{c}\text { Participación actores } \\
\text { locales }\end{array}$ \\
\hline $\begin{array}{l}\text { RBIM (España- } \\
\text { Marruecos) }\end{array}$ & $\begin{array}{l}\text { Sistema de Bosques } \\
\text { (Laurasilva; } \\
\text { Rododendros; } \\
\text { pinsapos; } \\
\text { Arconconales; } \\
\text { bosques litorales). } \\
\text { Reserva de agua como } \\
\text { eje fundamental. } \\
\text { Arqueología y } \\
\text { producción artesanal. } \\
905185 \text { ha. } \\
19 \text { espacios naturales } \\
\text { protegidos en España. } \\
9 \text { espacios protegidos } \\
\text { en Marruecos. }\end{array}$ & $\begin{array}{l}\text { Acciones en el marco INTERREG } \\
\text { III europeo y fondo del } \\
\text { programa POCTEFEX, a donde } \\
\text { Ilegan los recursos del FEDER. } \\
\text { Dos niveles: } \\
\text { 1. Transfronterizo: } \\
\text { incluye el Consejo de } \\
\text { dirección transfronterizo } \\
\text { (máximo ente); Junta } \\
\text { de coordinación } \\
\text { transfronteriza; Consejo } \\
\text { consultivo de cooperación } \\
\text { y Grupos de Trabajo } \\
\text { Transnacionales. } \\
\text { 2. Nacional: Comité de } \\
\text { coordinación y gestión } \\
\text { de la RBIM y Comité de } \\
\text { coordinación y gestión de } \\
\text { Andalucía. } \\
\text { Se da un acuerdo de } \\
\text { entendimiento entre las } \\
\text { partes, basado en la política } \\
\text { de fronteras de la uE y la } \\
\text { autonomía de las regiones. No } \\
\text { hay un tratado. }\end{array}$ & $\begin{array}{l}\text { Participan dentro del } \\
\text { consejo consultivo de } \\
\text { cooperación, intentando } \\
\text { comunicar a la población } \\
\text { los objetivos de la RBıM. } \\
\text { Formación de educadores } \\
\text { ambientales, participación } \\
\text { de las poblaciones como } \\
\text { dueñas de los saberes } \\
\text { tradicionales de la zona } \\
\text { y como receptores de } \\
\text { conocimiento técnico para } \\
\text { impulsar un modelo de } \\
\text { desarrollo racional. }\end{array}$ \\
\hline
\end{tabular}




\begin{tabular}{|c|c|c|c|}
\hline $\begin{array}{l}\text { Trifinio Fraternidad } \\
\text { (Honduras, } \\
\text { Guatemala y El } \\
\text { Salvador) }\end{array}$ & $\begin{array}{l}\text { Masa montañosa } \\
\text { conocida como } \\
\text { Monte de niebla } \\
\text { Montecristo. } \\
\text { Varios tipos de } \\
\text { bosque: } \\
\text { 1. De niebla. } \\
\text { 2. Transicionales. } \\
\text { 3. Mixtos (pinos y } \\
\text { robles). } \\
\text { 4. Bosques } \\
\text { subtropicales } \\
\text { secos. } \\
\text { 5. Bosques tropicales. } \\
\text { Cuencas del río } \\
\text { Lempa, Ulúa y } \\
\text { Motagua. } \\
\text { Interés alrededor de } \\
\text { los recursos forestales. } \\
7241 \text { km2 }\end{array}$ & $\begin{array}{l}\text { Se conforma por un tratado } \\
\text { entre tres países. } \\
\text { Comisión trasnacional } \\
\text { (dos vicepresidentes y un } \\
\text { delegado de la presidencia de } \\
\text { Honduras). } \\
\text { Secretaría ejecutiva } \\
\text { trasnacional: tres unidades } \\
\text { técnicas, una unidad } \\
\text { administrativa. } \\
\text { Comités consultivos: } \\
\text { Gobiernos locales, } \\
\text { mancomunidades, trinacional } \\
\text { y locales, cooperativas, varias } \\
\text { ONG y el sector privado. }\end{array}$ & $\begin{array}{l}\text { Alta institucionalidad, } \\
\text { paralela a los actores } \\
\text { locales, a partir de } \\
\text { la inclusión en el } \\
\text { arreglo institucional de } \\
\text { gobiernos locales y varias } \\
\text { mancomunidades de } \\
\text { distintas regiones dentro de } \\
\text { la reserva. } \\
\text { En la práctica, se presenta } \\
\text { una perspectiva muy } \\
\text { conservacionista y } \\
\text { excesivamente centralizada } \\
\text { sobre la zona. } \\
\text { No se genera interés de } \\
\text { participación de los actores } \\
\text { locales. Aun así, se presenta } \\
\text { como un espacio donde se } \\
\text { pueden posicionar agendas } \\
\text { y promover el desarrollo } \\
\text { local. }\end{array}$ \\
\hline
\end{tabular}

Fuente: elaboración propia a partir de Verdú-Baeza (2012); Molina-Vásquez y Villa-Díaz (2008); Consejería de Agricultura, Pesca y Medio Ambiente de Andalucía (2012); Florido del Corral y Clavero (2008); Hirezi (2011); Conato (2009); Artiga (sf); Task Team on South South Cooperation (2011); Barillas Morales y Chacón Góngora (2013); Tratado entre las Repúblicas de El Salvador, Guatemala y Honduras para la ejecución del Plan Trifinio (1987); Celata, Coletti y Sanna (2012).

En el ámbito de los recursos, se tienen en cuenta los recursos culturales y humanos en la conformación de la zona; además es de vital importancia la relación humano-medioambiental para entender la complejidad de dichos territorios. Respecto a los arreglos institucionales, vale la pena aclarar que un tratado constitutivo permite definir de forma clara el arreglo institucional requerido que comprometa a los Estados, teniendo en cuenta que la visión debe ser menos centralizada y con mayor poder de decisión de los actores locales debido a que la estructura organizacional vertical podría quitarle legitimidad a la cristalización del proceso.
Por último, en lo referente a la participación de los actores sociales, la construcción de una RBT debe estar vinculada a las necesidades de los actores, su papel debe ser activo, inserto en las dinámicas de decisión, estructuración y acción, cuestión que aparece en teoría dentro de ambos casos, pero que en ninguno logra cristalizarse de forma adecuada por la mencionada verticalidad que tiene el proceso y su excesiva mirada técnico-burocrática. Aunque las experiencias son disímiles por su contexto (el marco integracionista europeo frente al marco soberanista latinoamericano) tienen puntos de encuentro y complementariedades que son de interés para la formulación de una RBT en el caso de la reserva Seaflower, entre Colombia y Nicaragua. 
Compartiendo la Reserva Seaflower: construcción de una propuesta de reserva de biósfera transfronteriza

Se presentaron los estudios de caso de dos reservas transfronterizas en tres ámbitos: recursos, arreglos institucionales y la inclusión de sus actores locales en configuración de las reservas. La construcción de esta propuesta se presenta como alternativa para la resolución del conflicto limítrofe colombo-nicaragüense, basada en un acercamiento entre las poblaciones locales, donde estas definan las formas de administración, conservación y usos del recurso. Para ello, se revisarán tales ámbitos dentro de la reserva Seaflower; se darán a conocer los recursos existentes y los problemas pendientes por resolver en materia de los recursos susceptibles de ser apropiados (sistema de recursos y unidades de recursos); y los arreglos institucionales para el mantenimiento de la Reserva existentes en Colombia y la institucionalidad de Nicaragua. Lo anterior, para identificar los posibles acompasamientos institucionales y la capacidad de articulación de los actores locales, que impidan la aparición de posibles free riders a través de instituciones formales y no formales y sistemas de sanciones e incentivos que propendan por la conservación de recursos y se evite el sobreúso y la sobreexplotación y, posiblemente, el mal uso o usos ilegales del espacio.

También se espera delinear cuáles deben ser los actores que deben estar en el centro de la definición de los arre- glos institucionales, con lo cual no sólo se lograría la extensión política e institucional de la unidad ambiental efectiva de la reserva, sino que se daría respuesta al conflicto limítrofe interestatal a partir de los vínculos existentes entre los pobladores del Archipiélago y la costa Caribe nicaragüense.

\section{El sistema de recursos}

Como se mencionó al inicio, los RUC son un sistema de recursos y allí son apropiadas unidades de recurso por parte de apropiadores. Así, para entender la reserva Seaflower, es necesario caracterizar su sistema de recursos. En el Atlas de la Reserva de Biósfera Seaflower (CORALINA-INVEMAR, 2012) se presenta de manera amplia el entramado biológico, geofísico, cultural e institucional de la zona, con varias características importantes para la biósfera global y regional. Así se expresa el atlas sobre la reserva:

La Reserva de Biósfera Seaflower, abarca la extensión del Archipiélago. Dentro de sus límites se encuentra el AMP Seaflower, integrada por tres secciones: una de mayor extensión situada al Norte $\left(37522 \mathrm{~km}^{2}\right)$ que incluye los atolones de Quitasueño, Serrana y Roncador además de múltiples bancos profundos que no alcanzan a emerger; una sección central $\left(12716 \mathrm{~km}^{2}\right)$ que incluye el atolón de Old Providence y Santa Catalina y el Julio bank y la tercera sección en la parte sur $(14780$ $\mathrm{km}^{2}$ ) que incluye los atolones de San Andrés, East-South-East o Bo- 
lívar y South-South-West o Alburquerque y otros bancos como Far, Martínez y Meridiano 82. Si bien las secciones comparten ambientes similares dominados por corales, aguas transparentes y características oceánicas, cada una mantiene en sí misma sus particularidades y dinámicas, que hacen necesario generar acciones de manejo específicas para cada sección. Un diagnóstico de la visión espacial del archipiélago de San Andrés, Providencia y Santa Catalina general que mostró que los bancos objeto de la mayor explotación pesquera se localizan especialmente en la sección Norte o en los extremos más distantes de las secciones Centro y Sur, resalta, que las consideraciones de tipo limítrofe definen la necesidad de controlar áreas distantes para lo que se requerirían una infraestructura y presupuestos significativos, un escenario donde las acciones de control y vigilancia están directamente influenciadas por las decisiones políticas y por el diferendo limítrofe que persiste con Nicaragua respecto a los límites marinos y submarinos. (CORALINA-INVEMAR, 2012)

Dentro de la zona, se encuentra uno de los índices más altos de biodiversidad dentro del Mar Caribe, además de importantes ecosistemas como los arrecifes coralinos, pastos marinos y manglares, por lo que son áreas donde se pueden dar la conservación de otros recursos marinos (Comisión Colombiana del Océano, 2015, p. 20).
En cuanto a vegetación vascular, se encuentran cuatro unidades paisajísticas: Litoral arenoso, litoral rocoso, manglar y zona de transición entre manglar y vegetación terrestre donde se generan y sobreviven distintas especies (Murcia, 2012, p. 88). Dentro de los recursos se encuentra también el cangrejo negro, patrimonio natural de la reserva, distribuido por las tres grandes islas del archipiélago, aunque no uniformemente. El cangrejo negro está amenazado por la tala de bosques, incendios, captura directa y depredación por las especies introducidas llamadas maría mulata y lobo pollero (Llanos y Taylor, 2012, pp. 93-95).

En avifauna, según Lasso y García (2012, pp. 96-101), se ha identificado la presencia de cerca 612 individuos pertenecientes a 44 especies, clasificadas dentro de 16 familias. Del total de familias, $44 \%$ corresponden a especies residentes, $50 \%$ a especies migratorias y $5 \%$ a especies endémicas en la Isla de San Andrés, las cuales se localizan en gran medida en los manglares. Los autores además identificaron 531 aves correspondientes a 35 especies que hacen parte de 15 familias en Providencia y Santa Catalina; además, se habla de 9 especies de 3 familias en los cayos menores.

En cuanto a los recursos marinos, la isla de San Andrés cuenta con un área de $97,5 \mathrm{~km}^{2}$ de complejo arrecifal y una extensión coralina de más de 44 $\mathrm{km}^{2}$. Allí, se pueden encontrar comunidades como los corales pétreos, los 
peces arrecifales, invertebrados vágiles, esponjas, macroalgas y octocorales. Para Providencia y Santa Catalina se puede encontrar una barrera arrecifal extensa en donde se encuentran las mismas comunidades que en San Andrés (Abril-Howard y Bolaños, 2012, pp. 131-136).

En un estudio del fanerograma, Gómez y Bolaños (2012) han encontrado que en el archipiélago se encuentran más de 2000 hectáreas de pastos marinos, con cuatro especies vitales para la flora y fauna de la zona. En ellos se presenta una alta conectividad, a la cual los autores dan gran importancia debido a que, en su opinión:

[...] con la conectividad ecológica entre manglares, pastos marinos y arrecifes coralinos, la reducción de la cobertura de las áreas vegetadas o de cualquiera de los otros ecosistemas podrá causar alteraciones a las dinámicas naturales, con consecuencias aún desconocidas, pero que se sospechan pudieran ser severas dado su papel como refugio para larvas y juveniles de múltiples especies marinas de importancia comercial y ecológica, así como la alteración procesos de erosión/acreción en la zona costera. (pp. 139-143)

En lo referente a los bosques de manglar, se encuentran en las islas mayores, donde ocupan casi 207 hectáreas, los cuales se dividen en bosques de cuenca y de borde, todos con un alto grado de maduración y que suman 19 unidades entre bosque y parche de manglar, los cuales, a su vez, tienen un alto nivel de productividad en producción de hojas, ramas, flores y frutos (Machacón, Lasso y Ward, 2012).

Todos estos elementos hacen parte del sistema de recursos de la reserva Seaflower, como también el sistema íctico y el de los recursos no renovables que se encuentran en la zona. Como estos tienen un alto interés para la economía de los pobladores, será allí donde se enfoque el análisis de las unidades de recurso y bajo la cual se construirá la propuesta de este trabajo, de cara a la conformación de una RBT en la región del Gran Caribe.

\section{Los recursos ícticos y la pesca en la Seaflower}

El trabajo de Bolaños y sus colaboradores (2015) presentó una lista de 653 especies de peces conocidas, 487 de las cuales se encuentran en Providencia; un aproximado de 336-427 en las islas del sur, San Andrés y las islas del norte; y 210 especies en islas y bajos menores. Aunque debe tenerse en cuenta la anotación de Prada (2012) sobre este respecto:

Hay indicios de una leve recuperación en abundancia de peces y en riqueza de especies, quizá como resultado de las nuevas medidas de conservación tomadas en el AMP Seaflower, incluyendo un mayor control a la pesca furtiva, los cuales aún deben ser fortalecidos para poder determinar con certeza esta aparente recuperación. (p. 113) 
Dentro de las unidades de recurso destacables por el interés que suscitan para el comercio, la apropiación y el consumo, se encuentran la langosta espinosa, el caracol pala y una diversidad de peces serránidos. En distintos trabajos (Bent et al., 2011; Castro et al., 2008; Castro et al., 2007) se muestra no solo la importancia que tienen tales especímenes para las economías locales, sino los efectos negativos que se generan por el incumplimiento de las normatividades vinculadas a la pesca de este recurso, en términos de la sobrepesca y agotamiento, ante eventos como la captura de especímenes jóvenes, captura de hembras, pescas ilegales en tiempos de veda, entre otros.

Para el caso del caracol pala, se ha manifestado la importancia que revestiría del logro de acuerdos con otros países para el control de la pesca ilegal, ya que es uno de los recursos más extendidos en el Caribe. Además, se ha hecho manifiesta la preocupación por las incursiones a la zona de reserva para llevar a cabo actividades de pesca no controladas. Por ello, desde la Corporación para el Desarrollo Sostenible del Archipiélago de San Andrés, Providencia y Santa Catalina (CORALINA), se han llevado a cabo los estudios correspondientes a la caracterización de la pesca ilegal o no reglamentada y se ha incluido a los pescadores del archipiélago para llevar a cabo una estrategia de mantenimiento y control del recurso (Prada et ál., 2010).

Con estos recursos en juego y ante un escenario de indeterminación en las delimitaciones marítimas, la amenaza a los recursos es mayor, ya que se encuentran traslapadas las funciones de control sobre la zona de la reserva, y esto ha llevado a diversos desencuentros, con capturas de lado y lado, y amenaza a embarcaciones de pesca artesanal e industrial por las autoridades de ambos países ${ }^{6}$. Con ello se muestra la importancia que reviste lograr acuerdos transfronterizos que lleven a la cooperación para lograr ejercicios seguros de pesca y evitar la depredación de los recursos, vitales en las salidas de los pescadores a las aguas de la reserva.

\section{El arreglo institucional de la Seaflower}

Con el propósito de lograr estos ejercicios de cooperación, se debe entender cuál es la configuración institucional de la institución encargada de la administración de la reserva con lo cual se puede delimitar quiénes son los que están llevando el control de los recursos. CORALINA nació con la Ley 99 de 1993 y es quien hace el ejercicio de administración en la Seaflower. La Corporación, de acuerdo con Taylor y su equipo (2012), tiene

6 En Chacón Herrera (2016) se listan varios de los conflictos que se han generado en ejercicios de pesca. El más reciente es el rescate de una embarcación de bandera nicaragüense en el cayo de Serrana. También se listan los sucedidos en Serranilla con una embarcación colombiana y una nicaragüense. 
dentro de sus programas de acción los siguientes aspectos:

1. Manejo integrado del recurso hídrico

2. Protección y manejo de la biodiversidad

3. Manejo y protección del suelo y el subsuelo

4. Mejoramiento del empleo y mercados verdes

5. Desarrollo Institucional

6. Educación ambiental (p. 22).

Estos puntos muestran que hay una visión holística del manejo de la reserva en sus aspectos biofísicos, socioambientales y socioeconómicos.

Es de especial interés para el análisis el Acuerdo 001 de 2011, bajo el cual se establecen los Estatutos de la Corporación. Por un lado, debe destacarse la jurisdicción que se establece a la reserva, delimitada a todo el archipiélago junto con su mar territorial, y la zona económica de explotación exclusiva, que otorgan las porciones terrestres del archipiélago. Por otra parte, es vital destacar el arreglo institucional que se desprende del acuerdo, el cual define que serán tres los órganos de dirección y administración: la Asamblea Corporativa, el Consejo Directivo y el Director General.

De la primera, hacen parte los representantes legales de las entidades territoriales que integran la jurisdicción atribuida a la Corporación y entre sus funciones más importantes se encuentra la elección de los miembros del Consejo Directivo. El consejo es bastante heterogéneo, ya que incluye al gobernador del Departamento; un representante de Presidencia de la República; un delegado del Ministerio de medio ambiente; un secretario departamental de fomento agropecuario y pesquero; un representante de las ONG; un director de planeación departamental; al director de INVEMAR; al director de DIMAR; un representante de los gremios económicos del archipiélago; un representante de la comunidad nativa; un representante de la comunidad nativa de San Andrés; un representante de la comunidad nativa de Providencia y un representante de los gremios de la producción artesanal, agropecuaria y pesquera del archipiélago. Cabe destacar el amplio papel que tienen las comunidades y que las instituciones locales tienen fuerte participación dentro del Consejo Directivo, con lo cual se puede afirmar que la participación de los implicados directos es amplia.

Por último, el Director General, nombrado por el consejo, aunque no tiene autonomía de acción, por ser subsidiario del consejo. Es el representante legal de la corporación, presentará planes y programas al consejo, realiza informes al consejo y a Minambiente, convoca a reuniones y hace cumplir las decisiones o acuerdos de las otras dos instituciones.

Como se puede notar, CORALINA es una institución de raigambre local, con participación nacional pero que se construye desde los actores locales, lo cual le permite cumplir con 
los objetivos de las reservas de biósfera, vinculadas a la inclusión de las comunidades en la definición y discusión de políticas para el desarrollo sostenible sin afectar los intereses de estas. Esto es importante en un posible escenario de construcción de una RBT como forma de inclusión de los intereses de los directos implicados, para el logro de construcción de instituciones formales y no formales que permitan la conservación de la zona marítima en el Gran Caribe.

Pero, iqué institucionalidad existe en esta materia en Nicaragua? El país centroamericano cuenta con una Reserva de Biósfera en el territorio, Ilamada Bosawas, ya que consta de tres ríos, el Bocay, el Saslaya y el Waspuk. Más allá de una caracterización de los recursos, vale la pena concentrarse en el arreglo institucional que permita ver los posibles encuentros respecto a la institucionalidad de la Seaflower.

La institucionalidad de esta reserva queda expresada en la Ley 407 de 2001 en la que se declara y define la Reserva de Bosawas y está articulada a partir de la Comisión Nacional Bosawas, la cual se presenta como un órgano de consulta obligatoria de la cual hacen parte El Ministro de Ambiente de los Recursos Naturales, que preside la Comisión; el Ministro de Agropecuario o Forestal o su delegado; el Director de la Oficina de Titulación Rural (OTR) o su delegado; el Director del Instituto Nacional Forestal o su delegado; el Presidente del Con- sejo Regional Autónomo del Atlántico Norte o su delegado; los Alcaldes de Wiwilí de Jinotega, Nueva Segovia, Cuá-Bocay, Waslala, Siuna, Bonanza y Waspán junto con un representante de cada una de las comunidades Mískitu Indian Tasbaika Kum, Mayangna Sauni Bu, Kipla Sait Tasbaika, Mayangna Sauni As, Sikilta y LiLamni Tasbaika Kum.

Dentro de la Comisión Nacional, se establecieron funciones vinculadas a la proposición de políticas, la gestión financiera y técnica, y llevar a cabo la coordinación y vigilancia con la Secretaría Técnica de Bosawas. Dicha secretaría, cuyo director asigna el Ministerio de Ambiente y de los Recursos Naturales (MARENA), está a cargo de la organización y administración de la Reserva a partir de lo aprobado por la Comisión Nacional, además de proponer y participar en la elaboración de políticas, apoyar en la elaboración y propuesta de supervisión de las regulaciones de actividades que afecten la reserva.

Se puede afirmar que existe cierto nivel participativo de los actores locales, aunque no con la amplitud que se da en el caso de Seaflower, ya que aquí no hay una representación tan amplia de los distintos sectores sociales, tales como los gremios económicos, por ejemplo. Aun así, se ve también como una institucionalidad poco compleja, con apenas dos instancias que tienen un diálogo directo lo cual permite mejor manejo administrativo y ejecución de acciones. 


\section{Participación de los actores locales}

Para el caso de la Seaflower, se presenta un escenario positivo para la participación de los actores locales en términos de las instituciones gubernamentales, los gremios, la comunidad nativa en la construcción de políticas y toma de decisiones técnicas. En varios de los estudios de pesca mencionados, se ve la importancia que reviste el conocimiento de los pescadores en la definición de las acciones con respecto a la veda o a la apertura de las temporadas de pesca, la cantidad de recurso que puede ser apropiado. Además, las encuestas que se desarrollan se empatan con los estudios técnicos para lograr tener una perspectiva amplia sobre el manejo de los recursos pesqueros. También hay un ejercicio de participación en otros ámbitos como el manejo ambiental dentro de las Islas, el cuidado de todo el sistema de recursos, pero para el interés de este trabajo, el manejo de la pesca y la participación de los pescadores es vital, porque no sólo es uno de los mayores problemas en el espacio marítimo indefinido entre Colombia y $\mathrm{Ni}$ caragua, sino que puede ser el aspecto potencial que permita establecer una RBT entre ambos países.

\section{Conclusión}

Para concluir este trabajo, se presentan algunos aspectos que pueden impulsar el logro de una reserva de biósfera transfronteriza en la zona fronteriza entre Colombia y Nicaragua. Ya se ha dicho la circunstancia actual en la que se encuentra la reserva de biósfera Seaflower en términos de su indeterminación limítrofe y la tensión generada por la circunstancia nueva generada por el fallo de la CIJ en 2012 en el diferendo entre Colombia y Nicaragua. La alternativa que se propone aquí parte de que existen regímenes internacionales que podrían allanar el camino para suprimir dicha tensión y una alternativa para el abordaje de los bienes comunes que involucra a los actores locales y a las poblaciones de la zona.

Un primer régimen internacional está relacionado con el interés vinculado a las acciones de conservación del medio ambiente, ancladas a la reciente Acuerdo de París sobre el medio ambiente y el ya expresado marco de la UNESCO sobre las reservas de biósfera transfronterizas para la conservación del medio ambiente. Además, se encuentra el régimen de resolución pacífica de controversias, que ha llevado a que los Estados puedan zanjar disputas a través de medios pacíficos y acordes con el Derecho Internacional.

Como estos marcos son los que enmarcan la toma de decisiones, deben ser el sustento para llevar a un nuevo escenario transfronterizo la resolución de la indeterminación mencionada. Por ello, el mecanismo de RBT podría llevar a 1) resignificar los vínculos culturales entre las poblaciones que se encuentran en medio de la disputa; 2) que sean estas poblaciones, que tienen vocación internacional por sus constantes intercambios y acuerdos con sus pares fron- 
terizos, las que logren configurar un escenario de cooperación, mitigación de la incertidumbre y el conflicto y 3) Que dicho escenario sea presentado como un marco que delimite los papeles de conducta de los Estados imbricados en el conflicto, configure nuevas expectativas de cooperación y reconocimiento de la capacidad de acciones conjuntas y reconozca los mecanismos de incentivos y costos producidos por los actores locales, apoyándolos a través de sus estructuras institucionales. La comprensión por parte de los Estados de este escenario llevaría a mitigar las situaciones de indeterminación y conflicto, así como a identificar ganancias relativas que se presentan como deseables, pero requieren de una visión integracionista y no soberanista del conflicto.

Los arreglos institucionales logrados deben brotar del seno de los actores locales, las poblaciones afectadas por la indeterminación producida por el diferendo interestatal. Para ello, desde ambas partes se debe reconocer que acciones racionales pueden llevar a resultados indeseados ya que pueden devenir en una afectación al sistema de recursos y sus unidades de recurso. La comprensión de la interdependencia existente en el manejo de la Seaflower llevaría a que se pueda lograr una edificación de instituciones formales y no formales con su respectivo sistema de incentivos y castigos que debe consolidarse a través de las instituciones existentes a nivel local y de acciones de coordinación de quienes hacen uso de los recursos.
Una primera acción estaría orientada a que entidades como CORALINA en Colombia y MARENA en Nicaragua logren consolidar un acuerdo de cooperación, como instituciones a cargo del manejo de la Reserva, por medio de la elaboración de estrategias para intervenir en Seaflower. Estas instituciones deben estar a cargo de construir el puente entre las poblaciones locales para, por ejemplo, crear una comisión de pesca en la Reserva, donde se hagan partícipes las poblaciones raizales del Archipiélago de San Andrés, Providencia y Santa Catalina y los creoles de la Región del Atlántico tanto Norte como Sur en Nicaragua. En esta comisión se pueden establecer los tiempos de veda, los tiempos de pesca, el mantenimiento del recurso y los métodos de pesca, entre otros, y deberían ser los pobladores quienes definan su operatividad.

Los gobiernos locales deben dar soporte al marco jurídico y político en que se sustentarían las instituciones, las que podrían formalizar los acuerdos logrados por la comisión y las instituciones medioambientales, teniendo garantías de autonomía en la toma de decisiones y en la conformación de quienes entran en el proceso de toma de decisiones.

Los Estados tendrían que tener un papel de acompañamiento, brindando el apoyo económico, coercitivo (cuando se requiera) y de coordinación de acciones cuando las partes necesiten una intervención $y$, además, trabajando como gestores del 
reconocimiento de Seaflower como una RBT ante la UNESCO. Además, el marco jurídico nacional serviría como soporte para consolidar tratados binacionales que garanticen la resolución de conflictos vinculados al manejo de la reserva.

Las instituciones para el manejo compartido de la Reserva, desde una perspectiva de RBT, deben tener en cuenta los riesgos y las amenazas sobre el ecosistema que pueden surgir. Estos están vinculados a la identificación de los free-riders y las situaciones de gorroneo que pueden suceder $y$ que deben ser minimizados a través de los incentivos y los castigos que se definan.

Los free-riders que se pueden identificar son los pescadores industriales que puedan romper con las instituciones constituidas por los actores locales y que pueden llevar a cabo acciones de sobreúso y sobreexplotación. Otro de los free-riders son los distintos grupos que llevan a cabo acciones de narcotráfico y de transporte de drogas declaradas de uso ilícito, debido a que pueden romper con la esencia de los acuerdos institucionales logrados y además incrementar el conflicto entre las poblaciones, los actores locales y los Estados. Las situaciones de gorroneo pueden ser identificadas como ejercicios de pesca en tiempos de veda, o excesos en la pesca artesanal, como también excesivas atribuciones en los derechos que se definan dentro de las instituciones.
Por último, un arreglo institucional cristalizado desde lo local mitigaría los intereses estatales alrededor de la explotación petrolera, los planes vinculados a construcciones de canales para embarcaciones de gran calado y otros planes de interés nacional que irían en contravía de la conservación de la reserva Seaflower.

Todo esto puede empujar a la eliminación de la indeterminación limítrofe entre los Estados, lo que podría llevar a la firma de un tratado entre las partes que, como ya hemos visto en el caso del Trifinio, puede llevar a una zona de conservación estable y duradera. La firma de un tratado es un escenario deseable para las poblaciones y los actores locales, para la conservación del recurso y, sobre todo, para el reconocimiento del espacio fronterizo del Gran Caribe donde existe una historia común, una identidad común y una voluntad y vocación de trabajo conjunto que no pueden ser desconocidas por los Estados.

\section{Referencias}

Abril-Howard y A. Bolaños, N. (2012). Arrecifes de Coral. Atlas de la Reserva de la Biósfera Seaflower. Archipiélago de San Andrés, Providencia y Santa Catalina. Santa Marta, Colombia: Instituto de Investigaciones Marinas y Costeras José Benito Vives De Andréis - INVEMAR- y Corporación para el Desarrollo Sostenible del Archipiélago de San Andrés, Providencia y Santa Catalina -CO- 
RAlINA-. Serie de Publicaciones Especiales de INVEMAR, 28.

Añaños M. C. (2014). La idea de los bienes comunes en el Sistema Internacional: ¿Renacimiento o extinción? Anuario mexicano de Derecho Internacional. 14, 153-195.

Artiga, R. (sf). El caso del Trifinio en el Alto Lempa: Oportunidades y desafíos para la gestión compartida en Cuencas Transfronterizas de Centroamérica. Recuperado de: http://www.gwp.org/ Global/ToolBox/Case\%20Studies/ Americas\%20and\%20Caribbean/ Transboundary.\%20Opportunities $\% 20$ and $\% 20$ challenges $\% 20$ for $\% 20$ the $\% 20$ share $\% 20$ management $\% 20$ of $\% 20$ Watersheds; $\% 20$ the $\% 20$ Trifinio $\% 20$ Plan $\% 20$ for $\% 20$ the $\% 20$ Upper $\% 20$ Lempa $\% 20$ (\%23394)\%2OSPANISH.pdf

Barillas, W. A., Chacón, P. A. (2013). Diagnóstico para la determinación de comunidades críticas en el Área Protegida Trinacional Montecristo (APTM). Recuperado de: http://trinacionalriolempa.org/index.php/ the-joomla-community/estudios/ biblioteca/estudios/diagnosticopara-la-determinacion-de-comunidades-criticas-en-el-area-protegida-trinacional-montecristo-pdf/ download

Bent, H. Santos, A. Taylor y E. Pomare, C. (2011). Abundancia de grandes serránidos en la Reserva de Biósfera Seaflower. Proceedings of the $64^{\text {th }}$ Gulf and Caribbean Fisheries Institute. Recuperado de: http://www. gcfi.org/proceedings/sites/default/ files/procs/GCFI_64-46.pdf

Bolaños, N., Abril-Howard, A., Bent, H., Caldas, J. P. y Acero, A. (2015). Lista de peces conocidos del Archipiélago de San Andrés, Providencia y Santa Catalina, Reserva de Biósfera Seaflower, Caribe Occidental Colombiano. Boletín de Investigación Marinas y Costeras, 44(1), 127162.

Castro, E. García, M. Grandas, Y. y Pomare, M. (2007). Impactos de la pesquería de Langosta Espinosa con Nasas sobre comunidades bénticas y peces arrecifales en el Archipiélago de San Andrés, Providencia y Santa Catalina: Hacia una pesca responsable. $58^{\text {th }}$ Gulf And Caribbean Fisheries Institute. Recuperado de: http://aquaticcommons. org/13025/1/gcfi_58-48.pdf

Castro, E. Prada, M. Taylor, E. Daves, N. y Puentes, V. (2008). Mejorando la colaboración para el manejo del Caracol Pala. (Strombus gigas) en el Caribe Suroccidental. Proceedings of the 61th Gulf and Caribbean Fisheries Institute. Recuperado de http://www.gcfi.org/ proceedings/proceedings/mejorando-la-colaboraci\%C3\%B3n-parael-manejo-del-caracol-pala-strombus-gigas-en-el-caribe

Celata, F. Coletti, R. y Sanna, S. (2012). La reterritorialización de la Región del Trifinio: Las Mancomunidades locales y la difusión del modelo Europeo de Cooperación Transfronteriza en América Latina. Ponencia 
presentada en el XII Coloquio internacional de Geocrítica. Recuperado de: http://www.ub.edu/geocrit/coloquio2012/actas/11-V-Sanna.pdf

Chacón Herrera, C. (2016). Los náufragos de la indeterminación fronteriza. Observatorio OPRIC. http:// www.opric-unal.org/index.php/ produccion-academica/analisis-decoyuntura/1688-los-naufragos-dela-indeterminacion-fronteriza.html

Comisión Colombiana del Océano (2015). Aportes al conocimiento de la Reserva de Biósfera Seaflower. Bogotá: Comisión Colombiana del Océano.

Conato, D. (2009). Fronteras de tierra y de mar: De áreas conflictivas a espacios de colaboración e integración Centroamericana. En J. L. Rhi-Sausi, D. Conato y N. Oddone (Eds). Cooperación transfronteriza e integración en América Latina. Roma: CeSPI. pp. 103-140.

Consejería de Agricultura, Pesca y Medio Ambiente. Junta de Andalucía. (2012). Reserva de la Biósfera Intercontinental del Mediterráneo Andalucía (España)-Marruecos. Sevilla.

CORALINA-INVEMAR. (2012). Atlas de la Reserva de la Biósfera Seaflower. Archipiélago de San Andrés, Providencia y Santa Catalina. Santa Marta, Colombia: Instituto de Investigaciones Marinas y Costeras José Benito Vives De Andréis -INVEMAR- y Corporación para el Desarrollo Sostenible del Archipiélago de San Andrés, Providencia y Santa Catali- na -CORAlinA-. Serie de Publicaciones Especiales de INVEMAR, 28.

De Larramendi, M. H. (2003). EspañaMarruecos: "Una vecindad compleja". Ideas políticas. Recuperado de: http://www.iemed.org/observatori/arees-danalisi/arxius-adjunts/ afkar/afkar-ideas-1/larramendi.pdf/

Florido del Corral, D. y Clavero, J. (2008). La reserva de Biósfera Intercontinental del Mediterráneo (RBIM). Nuevas herramientas para viejos problemas. En J. P. OrialBeltrán e I. Vaccaro (Coords.), Patrimonialización de la naturaleza. El marco social de las políticas ambientales. Coordinado por, Serie, XI Congreso de Antropología de la FAAEE, Donostia, Ankulegi Antropologia Elkartea [en línea] www. ankulegi.org. 265-287.

Gómez, D.I. y Bolaños, N. (2012). Fanerógamas marinas. CORALINA-INVEMAR (Eds.). Atlas de la Reserva de la Biósfera Seaflower. Archipiélago de San Andrés, Providencia y Santa Catalina. Santa Marta, Colombia: Instituto de Investigaciones Marinas y Costeras José Benito Vives De Andréis -INVEMAR- y Corporación para el Desarrollo Sostenible del Archipiélago de San Andrés, Providencia y Santa Catalina -CORALINA-. Serie de Publicaciones Especiales de INVEMAR, 28.

Grasa, R. (2001). La construcción de regímenes internacionales para la protección transfronteriza del medio ambiente y los recursos naturales: isistemas de gobernación 
o sistemas de gobierno? Papeles y memorias de la Real Academia de Ciencias Morales y Políticas. 10. 112-133.

Hasenclever, A. Mayer, P. Rittberger, V. (1999). Las teorías de los regímenes internacionales: situación actual y propuestas para una síntesis. Foro Internacional, 39(4), 499-526.

Hernández Salinas, A. (2014). El reto de las Reservas de Biósfera Transfronterizas: De la conservación de la naturaleza a los acuerdos políticos. Forum de Sostenibilidad, 7, 13-31.

Hirezi, M. (2012). La cooperación intermunicipal transfronteriza en la región del Trifinio de El Salvador, Guatemala y Honduras. En A. Borbón, y B. Brealy (Eds.). América Latina y el Caribe: Cooperación Transfronteriza. De territorios de división a espacios de encuentro. Buenos Aires: Teseo, FLACSO.

Iglesias, M. (2010). Conflicto y cooperación entre España y Marruecos (1956-2008). Sevilla. Fundación Pública Andaluza Centro de Estudios Andaluces. Junta de Andalucía.

Keohane, R. O. (1993). Ensayos sobre la teoría de Relaciones Internacionales. Buenos Aires: Grupo Editor Latinoamericano.

Lasso, J. García, M. I. (2012). Composición de la avifauna de la zona costera de la Reserva de Biósfera Seaflower. En CORALINA-INVEMAR (Eds). Atlas de la Reserva de la Biósfera Seaflower. Archipiélago de San Andrés, Providencia y Santa Catalina. Santa Marta, Colombia: Insti- tuto de Investigaciones Marinas y Costeras José Benito Vives De Andréis -INVEMAR- y Corporación para el Desarrollo Sostenible del Archipiélago de San Andrés, Providencia y Santa Catalina -CORALINA-. Serie de Publicaciones Especiales de INVEMAR \# 28.

Llanos, C. y Taylor, M. (2012). El Cangrejo Negro, patrimonio Natural de la Reserva de Biósfera Seaflower. En CORALINA-INVEMAR (Eds). Atlas de la Reserva de la Biósfera Seaflower. Archipiélago de San Andrés, Providencia y Santa Catalina. Santa Marta, Colombia: Instituto de Investigaciones Marinas y Costeras José Benito Vives De Andréis -INVEMAR- y Corporación para el Desarrollo Sostenible del Archipiélago de San Andrés, Providencia y Santa Catalina -CORALINA-. Serie de Publicaciones Especiales de INVEMAR, 28.

Machacón, I. Lasso, J. y Ward, V. (2012). Bosques de Manglar En CORALINA-INVEMAR (Eds). Atlas de la Reserva de la Biósfera Seaflower. Archipiélago de San Andrés, Providencia y Santa Catalina. Santa Marta, Colombia: Instituto de Investigaciones Marinas y Costeras "José Benito Vives De Andréis" -INVEMAR- y Corporación para el Desarrollo Sostenible del Archipiélago de San Andrés, Providencia y Santa Catalina -CORALINA-. Serie de Publicaciones Especiales de INVEMAR, 28.

Mantilla, S. C., Chacón Herrera, C. Román Romero, R. (2016). Toward bulding a Cross-Border Integration Region among Five Caribbean 
Countries. Revista Frontera Norte, 28(56), 5-33.

Mantilla Valbuena, S. C. y Chacón Herrera, C. (2016). Balance comparativo de la normatividad sobre fronteras en cuatro países colindantes del Caribe. Estudios Fronterizos, 17(34), 1-20.

Molina Vásquez, F. y Villa Díaz, Á. (2008). La Reserva de Biósfera Intercontinental de Mediterráneo Andalucía (España) - Marruecos como instrumento de cooperación. ECOsistemas, 17(2), 17-27.

Murcia, G. (2012). Vegetación vascular terrestre del borde litoral del Archipiélago de San Andrés, Providencia y Santa Catalina. En CORALINA-INVEMAR (Eds). Atlas de la Reserva de la Biósfera Seaflower. Archipiélago de San Andrés, Providencia y Santa Catalina. Santa Marta, Colombia: Instituto de Investigaciones Marinas y Costeras José Benito Vives De Andréis -INVEMAR- y Corporación para el Desarrollo Sostenible del Archipiélago de San Andrés, Providencia y Santa Catalina -CORAlinA-. Serie de Publicaciones Especiales de INVEMAR, 28.

Nicaragua y Colombia deberán compartir Reserva Seaflower. (2013). El Nuevo Diario. 30 de agosto. Recuperado de: http://www.elnuevodiario. com.ni/politica/295533-nicaraguacolombia-deberan-compartir-reserva-seafl/

Ostrom, E. (2000). El Gobierno de los Bienes Comunes. La evolución de las instituciones de acción colectiva.
México: Fondo de Cultura Económica. Primera Edición.

Ostrom, E. (2008). A general framework for analyzing Sustainability of Social-Ecological Terms. Science, 325(419), 419-422.

Peña Medina, S. (2011) Regímenes de planificación transfronteriza: México-Estados Unidos. Frontera y Sociedad, 23(50), 115-151.

Pool Stanvliet, Ruida. 2013. "A history of the UNESCO Man and the Biosphere Programme in South Africa". South African Journal of Science, 109 (9-10), 1-6.

Prada, M. (2012). Comunidad de peces. En CORALINA-INVEMAR (Eds.) Atlas de la Reserva de la Biósfera Seaflower. Archipiélago de San Andrés, Providencia y Santa Catalina. Santa Marta, Colombia: Instituto de Investigaciones Marinas y Costeras José Benito Vives De Andréis -INVEMAR- y Corporación para el Desarrollo Sostenible del Archipiélago de San Andrés, Providencia y Santa Catalina -CORAlINA-. Serie de Publicaciones Especiales de INVEMAR, 28.

Prada, M. Castro, E. Britton, A. Bent, O. Taylor, E. Hugdson, R. (2010). Estrategias para afrontar la pesca ilegal, no declarada o no reglamentada en la Reserva de Biósfera Seaflower, Caribe Occidental. Proceedings of the $63^{\text {rd }}$ Gulf and Caribbean Fisheries Institute. Recuperado de: www. gcfi.org/proceedings/sites/default/ files/procs/GCFI_63-70.pdf 
Resolución 28 C/ 2.4 de la Conferencia General de la Unesco. (1995). Reservas de Biósfera. La estrategia de Sevilla y el Marco Estatutario de la Red Mundial. Paris: UNESCO.

Strange, S. (2009). Cave! Hic Dragones. Una crítica del análisis de regímenes. Relaciones Internacionales, 12, 125-143.

Task Team on South South Cooperation. (2011). Cooperación en la Región de Trifinio: Un caso de cooperación transfronteriza Sur-Sur. Estudio de Caso. Recuperado de http://www.southsouthcases.info/ pdf/lac13.pdf.

Taylor, E. Howard, M. Medina, R: Bent, O. (2012). En CORALINA-INVEMAR (Eds.) Gestión Ambiental en la Reserva de la Biósfera Seaflower, archipiélago de San Andrés, Providencia y Santa Catalina, Caribe Occidental, Colombia. Atlas de la Reserva de la Biósfera Seaflower. Archipiélago de San Andrés, Providencia y Santa Catalina. Santa Marta, Colombia: Instituto de Investigaciones Marinas y Costeras José Benito Vives De Andréis -INVEMAR- y Cor- poración para el Desarrollo Sostenible del Archipiélago de San Andrés, Providencia y Santa Catalina -CORALINA-. Serie de Publicaciones Especiales de INVEMAR, 28.

Tratado entre las Repúblicas de El Salvador, Guatemala y Honduras para la ejecución del Plan Trifinio. (1987). Recuperado de: https://www.oas. org/dsd/publications/Unit/oea29s/ oea29s.pdf

UNESCO. (2000). Recomendaciones para el establecimiento y funcionamiento de las reservas de biósfera. Recuperado de: http://rerb.oapn. es/images/PDF_publicaciones/ mab_rb_transfronterizas_tcm 745368.pdf

Valencia, J. (1986). La organización internacional del Programa El Hombre y la Biósfera. Ambiente y Desarrollo 2(1), 107-110.

Verdú-Baeza, J. (2012). El medio ambiente como instrumento de cooperación transfronteriza: La Reserva de la Biósfera Intercontinental del Mediterráneo entre Andalucía y Marruecos. Anuario español de Derecho Internacional, 28, 397-416. 
